\title{
UNIFORM FRACTIONAL FACTORIAL DESIGN TABLES FOR ENERGY PILES WITH MAXIMUM THERMAL CONDUCTANCE
}

\author{
KHALED AHMED ${ }^{1}$, MOHAMMED AL-KHAWAJA ${ }^{1}$ \& MUHANNAD SULEIMAN ${ }^{2}$ \\ ${ }^{1}$ Mechanical \& Industrial Engineering Department, Qatar University, Qatar \\ ${ }^{2}$ Civil and Environmental Engineering, Lehigh University, USA
}

\begin{abstract}
Energy Piles are the heat exchangers of Ground Source Heat Pumps (GSHP) that transfer the buildings heat to the lower temperature shallow ground reducing the energy consumption in the cooling of buildings. These piles are designed with main objective of lowest thermal resistance. In this paper, nine factors influencing the thermal resistance of the energy pile are defined and statistically evaluated. These nine factors are; number of tubes, pile diameter, tube diameter, tube thickness, tube location, pile conductivity, tube conductivity, soil conductivity, and water flow rate. The thermal resistance of the energy pile is calculated using the line source analytical model. The significance of these factors is evaluated using fractional factorial uniform design tables. The results show significant decrease in the pile thermal resistivity with the increase of the tube diameter, number of tubes, water flow rate, and tube and pile thermal conductivities. On the other hand, decrease of the tube thickness, and pile diameter slightly decrease the pile thermal resistivity. Furthermore, the tubes located near the piles outer surface show significant decrease in the pile thermal resistivity. Also, the soil thermal conductivity has shown insignificant effects on the pile thermal resistivity.
\end{abstract}

Keywords: GSHP, energy pile, thermal resistivity, heat transfer, renewable energy, geothermal.

\section{INTRODUCTION}

Ground Source Heat Pumps (GSHP) are geothermal free forms of energy that utilize the constant temperature of the shallow ground all year round to reduce energy consumption in cooling buildings through its energy piles [1]. The significant advantage of using energy piles over borehole systems is that they require no additional structural or hydraulic measures because they are installed within elements that are already needed for structure [2]. Energy piles utilize renewable geothermal energy for buildings heating and cooling purposes and need proper design and sizing in order to end up with high plant efficiency [3].

Due to the increase of using GSHP systems, local temperature anomalies (cold or heat plumes) have been observed [4]. This shows the necessity to consider environmental and technical criteria to guarantee its sustainability [5]. As such, development of an integrated management system to organize the exploitation of this resource it is mandatory to protect both ground temperature and the users' rights [6]. Development of legislation framework for energy and environmental sources management [7], requires robust correlation of the effect of the GSHP controlling factors on the final energy piles thermal conductance.

Research on the controlling factors of the energy piles have shown that maximizing the pile surface that are for heat transfer, maximizing the concrete thermal conductivity, and maximizing the number of water tubes will increase the heat exchange through the energy pile [8]. These reports did not include all elements affecting the thermal resistivity of energy pile. The analytical formulae proposed by [9], have shown nine factors that affect the energy pile steady state thermal resistance. These nine factors are; number of tubes, pile diameter, tube diameter, tube thickness, tube location, pile, tube and soil thermal conductivities, and water flow rate. Investigating these factors together require an unreachable number of 
experiments to evaluate the interrelation between these controlling factors. Statistical design of experiments methods like uniform fractional factorial design can solve this problem [10].

The objective of the current work is to define a correlation between the controlling factors based on the significance of each of these factors on the energy pile steady state thermal resistivity while changing other factors using uniform fractional factorial design of experiment method.

\section{ENERGY PILE FACTORS}

The current work considers the energy pile cross sectional in plane factors assuming same behaviors and relations through the pile height. Fig. 1 shows schematic configurations of the studied energy piles in the current work. The steady state thermal resistance formulae for these energy pile configurations are approximated analytically by [9], as follows;

Single U-tube;

$$
R_{p}=\frac{1}{2 \pi K_{p}}\left[\ln \left(\frac{d_{p}^{2}}{2 n d_{o} S}\left(\frac{d_{p}^{4 n}}{d_{p}^{4 n}-S^{4 n}}\right)^{\bar{K}}\right)\right]+R_{t}
$$

Double U-tube;

$$
R_{p}=\frac{1}{4 \pi K_{p}}\left[\ln \left(\frac{d_{p}^{2 n}}{2 n d_{o} S^{2 n-1}}\left(\frac{d_{p}^{4 n}}{d_{p}^{4 n}-S^{4 n}}\right)^{\bar{K}}\right)\right]+R_{t}
$$

Triple U-tube;

$$
\begin{aligned}
R_{p}=\frac{1}{6 \pi K_{p}}\left[\ln \left(\frac{d_{p}^{2 n}}{2 n d_{o} S^{2 n-1}}\right)\right. & \\
& \left.\quad+\ln \left(\frac{d_{p}^{4 n}}{\left(d_{p}^{m}-S^{m}\right)\left(d_{p}^{2 m}+S^{2 m}+d_{p}^{m} S^{m}\right)}\right)^{\bar{K}}\right]+R_{t}
\end{aligned}
$$

where;

$R_{p}[\mathrm{~m} . \mathrm{K} / \mathrm{W}]$ : Energy pile thermal resistance

$n$ : Number of U-tubes

$m=2(n-1)$

$d_{p}[\mathrm{~m}]$ : Pile diameter.

$d_{i}[\mathrm{~m}]$ : Tube inner diameter

$t[\mathrm{~m}]$ : Tube thickness

$S[\mathrm{~m}]$ : Tubes spacing.

$K_{p}[\mathrm{~W} / \mathrm{m} . \mathrm{K}]$ : Pile thermal conductivity.

$K_{s}[\mathrm{~W} / \mathrm{m} . \mathrm{K}]$ : Soil thermal conductivity.

$K_{t}[\mathrm{~W} / \mathrm{m} . \mathrm{K}]$ : Tube thermal conductivity.

$$
\begin{aligned}
\bar{K} & =\left(\frac{K_{p}-K_{s}}{K_{p}+K_{s}}\right) \\
R_{t} & =\frac{1}{2 n \pi}\left(\frac{1}{2 K_{t}} \ln \left(\frac{d_{o}}{d_{i}}\right)+\frac{1}{d_{i} H}\right)
\end{aligned}
$$

$H\left[\mathrm{~W} / \mathrm{m}^{2} . \mathrm{K}\right]$ : Convection heat transfer coefficient. 


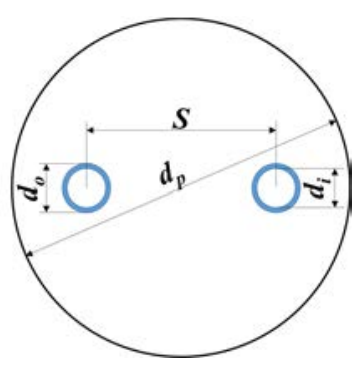

(a)

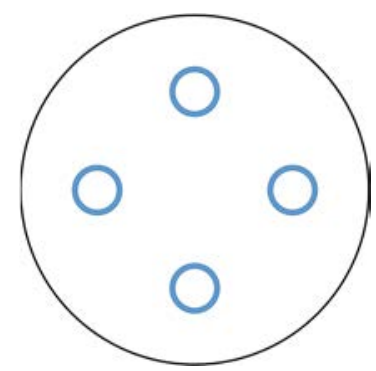

(b)

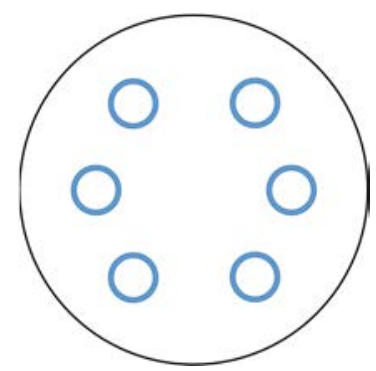

(c)

Figure 1: Energy pile geometrical factors. (a) Single U-tube; (b) Double U-tube; (c) Triple U-tube.

These relations have nine common factors that are controlling the steady state thermal resistance of the energy pile. Defining a quadratic correlation of these factors towards achieving the minimum resistance can be achieved at certain combination of these factors, which can be achieved by using design of experimental methods.

Design of experiment methods are widely used in factors correlations and performance optimizations of multivariable systems [10]. Fractional factorial design of experiment is optimally suitable for systems with a large number of factors like the thermal resistance of energy pile. The Uniform design is an efficient fractional factorial design [11]. The uniform design is one of the robust space-filling designs that is significantly important in investigating large system engineering [12].

\section{UNIFORM DESIGN}

\subsection{Design creation}

The domain of each factor of the energy pile system nine factors is leveled to three levels $(-1,0,+1)$. The related values of these levels for each factor are listed in Table 1 . The design $\left(3^{9}\right)$ can be investigated through a number of runs as low as 9 runs and as high as 51 runs. The number of runs affect the discrepancy of the uniformity of the design table. Fig. 2 presents the effect of the number of runs on the discrepancy $\mathrm{CD}_{2}$ of the design $\mathrm{U}_{\mathrm{n}}\left(3^{9}\right)$ [13]. The current work uses the uniform designs $\mathrm{U}_{27}\left(3^{9}\right), \mathrm{U}_{36}\left(3^{9}\right)$ and $\mathrm{U}_{51}\left(3^{9}\right)$ with 27,36 and 51 runs respectively [13]. Uniform design $\mathrm{U}_{51}\left(3^{9}\right)$ is shown in Table 2, and the other designs are available at the Uniform Design Tables book [13].

The energy pile thermal resistance is calculated at each run using the related factors assigned by the UD table. It is worth noting that the correlation between the pile components thermal conductivities and the reciprocal of the pile resistance is physically preferred. The reciprocal of the calculated resistances are shown in the last column in Table 2 . These values are analyzed in the next sections using stepwise a quadratic regression model. 


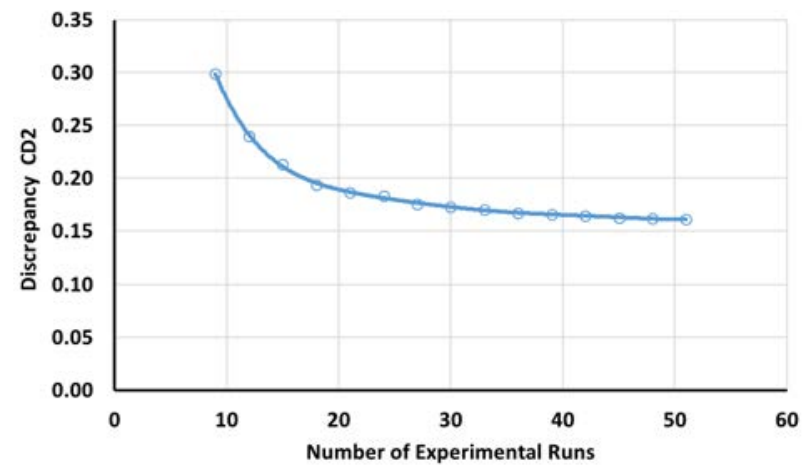

Figure 2: Effect of number of runs on the uniform design Un(39) discrepancy CD2 edited based on the data published by [13].

Table 1: Studied factors and its levels.

\begin{tabular}{|c|c|c|c|c|c|c|c|c|c|}
\cline { 2 - 10 } \multicolumn{1}{c|}{} & $n$ & $d_{p}$ & $d_{i}$ & $T$ & $S$ & $K_{p}$ & $K_{s}$ & $K_{t}$ & $H$ \\
\hline-1 & 2 & 0.4 & 0.02 & 0.002 & $0.25 d_{p}$ & 1.0 & 0.5 & 0.4 & 10 \\
\hline 0 & 4 & 0.7 & 0.03 & 0.003 & $0.50 d_{p}$ & 1.75 & 1 & 0.5 & 20 \\
\hline+1 & 6 & 1.0 & 0.04 & 0.004 & $0.75 d_{p}$ & 2.25 & 1.5 & 0.6 & 30 \\
\hline
\end{tabular}

Table 2: Uniform design $\mathrm{U}_{51}\left(3^{9}\right)$ [13].

\begin{tabular}{|c|c|c|c|c|c|c|c|c|c|c|c|}
\cline { 2 - 13 } \multicolumn{1}{c|}{} & $n$ & $d_{p}$ & $d_{i}$ & $t$ & $S$ & $K_{p}$ & $K_{s}$ & $K_{t}$ & $H$ & $R_{p}$ & $\begin{array}{c}\text { Conductance } \\
1 / R_{p}\end{array}$ \\
\hline 1 & 1 & 1 & 1 & 1 & 1 & 0 & -1 & -1 & 1 & 0.128 & 7.84 \\
\hline 2 & 0 & 1 & -1 & 0 & 1 & -1 & 0 & 1 & 1 & 0.440 & 2.27 \\
\hline 3 & 1 & -1 & 1 & 1 & -1 & 0 & 1 & 0 & 0 & 0.216 & 4.64 \\
\hline 4 & 0 & -1 & 1 & -1 & 0 & 1 & -1 & -1 & -1 & 0.328 & 3.05 \\
\hline 5 & -1 & 0 & 0 & 1 & 1 & -1 & 1 & 0 & 1 & 0.537 & 1.86 \\
\hline 6 & -1 & 1 & 0 & 1 & 0 & -1 & 1 & 1 & 0 & 0.726 & 1.38 \\
\hline 7 & 1 & 0 & 0 & -1 & -1 & 1 & 1 & -1 & 1 & 0.193 & 5.17 \\
\hline 8 & 0 & 0 & 0 & 0 & 0 & 0 & 0 & 0 & 0 & 0.310 & 3.22 \\
\hline 9 & 0 & 0 & 0 & 1 & 1 & -1 & -1 & -1 & 0 & 0.341 & 2.93 \\
\hline 10 & 0 & 1 & -1 & -1 & 0 & 1 & 1 & 0 & 1 & 0.371 & 2.70 \\
\hline 11 & 0 & 1 & 0 & 1 & -1 & 1 & -1 & 0 & -1 & 0.526 & 1.90 \\
\hline 12 & 0 & 1 & 1 & 0 & -1 & -1 & 1 & -1 & 1 & 0.349 & 2.86 \\
\hline 13 & 1 & 1 & 0 & 1 & 1 & 1 & 0 & 1 & 0 & 0.186 & 5.37 \\
\hline 14 & 0 & 0 & 0 & 0 & 0 & 0 & 0 & 0 & 0 & 0.310 & 3.22 \\
\hline 15 & -1 & 0 & 0 & 1 & -1 & 0 & 0 & -1 & -1 & 1.041 & 0.96 \\
\hline 16 & -1 & -1 & 1 & 0 & 1 & 1 & 1 & 0 & 1 & 0.273 & 3.67 \\
\hline 17 & 1 & 1 & 1 & 0 & 0 & 1 & 0 & 0 & 0 & 0.156 & 6.42 \\
\hline 18 & 0 & 0 & 1 & 1 & 1 & 1 & 1 & 0 & -1 & 0.323 & 3.10 \\
\hline 19 & 0 & -1 & 0 & 0 & 0 & 0 & 0 & -1 & 1 & 0.237 & 4.23 \\
\hline 20 & 1 & -1 & 0 & 0 & -1 & -1 & -1 & 0 & 1 & 0.320 & 3.12 \\
\hline 21 & 1 & 0 & 1 & -1 & 0 & -1 & 0 & 0 & 1 & 0.190 & 5.26 \\
\hline 22 & -1 & 0 & -1 & 0 & -1 & 1 & 1 & 1 & 0 & 1.000 & 1.00 \\
\hline
\end{tabular}


Table 2: Continued.

\begin{tabular}{|c|c|c|c|c|c|c|c|c|c|c|c|}
\cline { 2 - 11 } \multicolumn{1}{l|}{} & $n$ & $d_{p}$ & $d_{i}$ & $t$ & $S$ & $K_{p}$ & $K_{s}$ & $K_{t}$ & $H$ & $R_{p}$ & $\begin{array}{c}\text { Conductance } \\
1 / R_{p}\end{array}$ \\
\hline 23 & 1 & 0 & -1 & -1 & 1 & 1 & -1 & 0 & 0 & 0.328 & 3.05 \\
\hline 24 & -1 & 0 & -1 & -1 & 0 & -1 & -1 & -1 & 1 & 0.910 & 1.10 \\
\hline 25 & -1 & 1 & 1 & 0 & 1 & -1 & -1 & 0 & -1 & 0.802 & 1.25 \\
\hline 26 & -1 & 0 & 1 & 1 & 0 & 1 & -1 & 1 & 1 & 0.302 & 3.31 \\
\hline 27 & -1 & 1 & -1 & 0 & 1 & 1 & 0 & -1 & -1 & 1.809 & 0.55 \\
\hline 28 & 1 & -1 & 0 & -1 & 1 & -1 & 0 & -1 & -1 & 0.343 & 2.92 \\
\hline 29 & 1 & 1 & -1 & 1 & 0 & -1 & 1 & -1 & -1 & 0.715 & 1.40 \\
\hline 30 & -1 & 1 & 0 & -1 & 1 & 0 & 1 & -1 & 0 & 0.587 & 1.70 \\
\hline 31 & 0 & 1 & 1 & 0 & 0 & 0 & 1 & 1 & -1 & 0.369 & 2.71 \\
\hline 32 & 1 & -1 & 0 & 0 & 0 & 1 & 1 & 1 & -1 & 0.326 & 3.06 \\
\hline 33 & 1 & -1 & -1 & 0 & 0 & -1 & -1 & 1 & 0 & 0.425 & 2.35 \\
\hline 34 & -1 & 1 & 1 & -1 & -1 & 1 & 0 & -1 & 0 & 0.420 & 2.38 \\
\hline 35 & 0 & 0 & -1 & -1 & 1 & 0 & 0 & 0 & -1 & 0.900 & 1.11 \\
\hline 36 & 0 & -1 & -1 & 0 & 1 & 0 & 1 & -1 & 0 & 0.506 & 1.98 \\
\hline 37 & 0 & -1 & 1 & 1 & -1 & -1 & 0 & 1 & -1 & 0.485 & 2.06 \\
\hline 38 & 1 & 1 & -1 & -1 & -1 & 0 & 0 & 1 & -1 & 0.692 & 1.44 \\
\hline 39 & -1 & -1 & 1 & -1 & -1 & 0 & 0 & 1 & 1 & 0.337 & 2.97 \\
\hline 40 & 0 & 1 & 0 & -1 & -1 & -1 & -1 & 1 & 0 & 0.470 & 2.13 \\
\hline 41 & -1 & -1 & -1 & -1 & -1 & -1 & 1 & 0 & -1 & 1.967 & 0.51 \\
\hline 42 & -1 & 1 & -1 & 0 & -1 & 0 & -1 & 0 & 1 & 0.825 & 1.21 \\
\hline 43 & 1 & -1 & -1 & 1 & 0 & 1 & 0 & 0 & 1 & 0.263 & 3.80 \\
\hline 44 & 1 & 0 & 1 & 0 & -1 & 0 & -1 & -1 & -1 & 0.320 & 3.12 \\
\hline 45 & 0 & -1 & 0 & -1 & 1 & 1 & -1 & 1 & 1 & 0.182 & 5.49 \\
\hline 46 & -1 & 0 & 0 & -1 & 0 & 0 & -1 & 1 & -1 & 0.975 & 1.03 \\
\hline 47 & -1 & -1 & -1 & 1 & 1 & 0 & -1 & 1 & -1 & 1.802 & 0.56 \\
\hline 48 & 0 & -1 & -1 & 1 & -1 & 1 & -1 & -1 & 0 & 0.550 & 1.82 \\
\hline 49 & 1 & 0 & 1 & -1 & 1 & -1 & 1 & 1 & 0 & 0.159 & 6.28 \\
\hline 50 & 1 & 0 & -1 & 1 & -1 & 0 & 1 & 1 & 1 & 0.337 & 2.96 \\
\hline 51 & -1 & -1 & 1 & 1 & 0 & -1 & 0 & -1 & 0 & 0.500 & 2.00 \\
\hline & & & & & & & & & & & \\
\hline
\end{tabular}

\subsection{Signal to noise ratio}

Measured quantities are affected by significant and insignificant factors. Significant factors produce a strong signal while insignificant factors produce noise. Magnification of the signal to noise ratio emphasizes the effect of each factor on the measured data. This leads to optimizing the controlling factors for better performance. The signal to noise ratio is measured for each factor through its measured range $(-1,0,+1)$. The signal to noise ratio in the current work is calculated with the following equation for minimizing the energy pile thermal resistance;

where;

$$
S / N=-10 \log _{10}\left(\frac{1}{m} \sum_{i=1}^{m} R_{p, i}^{2}\right)
$$

$m$ : is the number of observations for each factor.

$R_{p, i}^{2}$ is the observed thermal resistance at experiment number $\mathrm{i}$ 


\subsection{Quadratic correlation}

Another method to investigate the significance for each factor is the estimation of the quadratic least square modelling of the observed data of all the experiments. The common quadratic correlation is simply expressed as follows;

$$
Y=a_{0}+\sum_{k=1}^{9} a_{k} x_{k}+\sum_{i=1}^{9} \sum_{j=i}^{9} b_{i j} x_{i} x_{j}
$$

where;

$\mathrm{Y}$ represents a function of the equivalent thermal resistance of the energy pile including water tubes.

$a_{0}, a_{k}$, and $b_{i j}$ are the correlation coefficients of the quadratic model. These coefficients can be calculated using stepwise least square method.

The first part is the intercept constant. The second part represents the linear weight of each factor separately. Lastly the third part represents the quadratic and the interaction between controlling factors in a pair wise manner. It is worth noting that the right-hand side of the quadratic equation includes the thermal conductivities of the energy pile components, so it is more logical to consider the left-hand side of the quadratic equation as the energy pile conductance. Consequently, Y is the reciprocal of the energy pile thermal resistance. The related factors for each variable in the quadratic relation is shown in Table 3.

Table 3: The related factors for each variable in the quadratic correlation.

\begin{tabular}{|c|c|c|c|c|c|c|c|c|}
\hline$x_{1}$ & $x_{2}$ & $x_{3}$ & $x_{4}$ & $x_{5}$ & $x_{6}$ & $x_{7}$ & $x_{8}$ & $x_{9}$ \\
\hline$n$ & $d_{p}$ & $d_{i}$ & $T$ & $S$ & $K_{p}$ & $K_{s}$ & $K_{t}$ & $H$ \\
\hline
\end{tabular}

\section{RESULTS}

\subsection{Signal to noise ratio}

The significance of each factor is measured by calculating the mean thermal resistance for each factor with all other factors. The three designs have shown consistent behaviour with the most significant factors. On the other hand, the less significant factors have shown nonconsistent behaviour with the three designs. The most five significant factors with direct proportionality are the number of tubes " $n$ ", the tube inner diameter " $d_{i}$ ", the convection heat transfer coefficient " $H$ ", the pile thermal conductivity " $K_{p}$ ", and the distance between tubes " $S$ " respectively in significance order. The other four factors are either less significant or with inverse proportionality.

The calculated signal to noise ratios of these thermal resistances measured means of the energy pile at the different runs and using the different designs are analysed using smalleris-better eqn. (4). The design $U_{27}\left(3^{9}\right)$ shows high noises in all cases as shown in Fig. 3. The designs $\mathrm{U}_{36}\left(3^{9}\right)$ and $\mathrm{U}_{51}\left(3^{9}\right)$ have shown noises with the less significant factors; pile diameter " $d_{p}$ ", tube thickness " $t$ ", soil thermal conductivity " $K_{s}$ ", and the tube thermal conductivity " $K t$ ". The other factors have shown smallest signal to noise ratio at the highest level " +1 ". These factors are the number of tubes " $n$ ", the tube inner diameter " $d_{i}$ ", the convection heat transfer coefficient " $H$ ", the pile thermal conductivity " $K_{p}$ ", and the distance between tubes " $S$ " respectively in significance order, as shown in Fig. 3. 

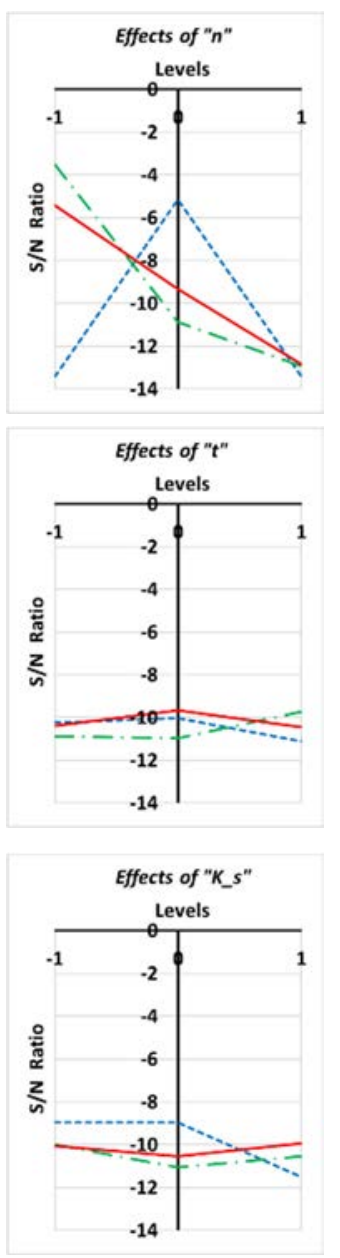
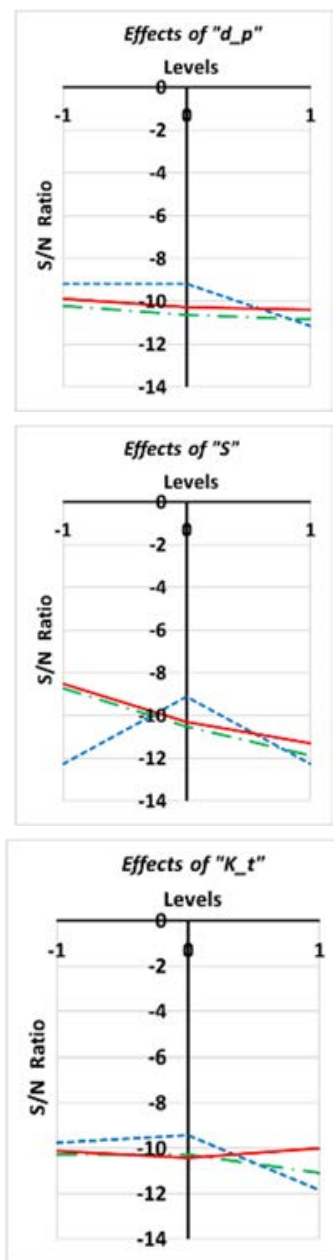

$\mathrm{U}_{27}\left(3^{9}\right)$

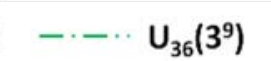

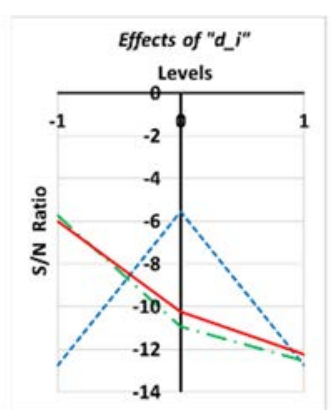
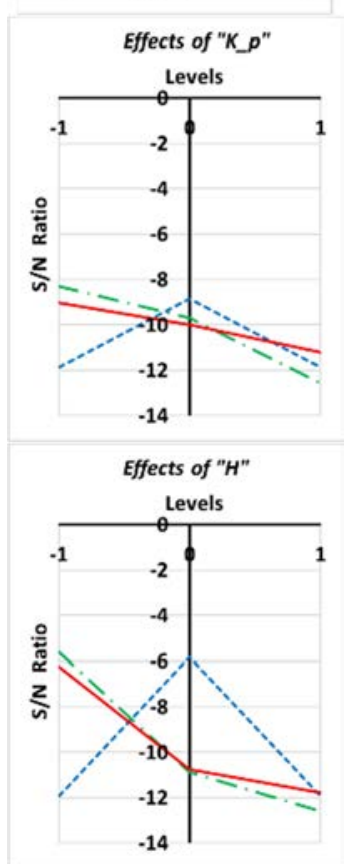

$\mathrm{U}_{51}\left(3^{9}\right)$

Figure 3: Signal to noise ratios of the energy pile thermal resistance predicted at different uniform designs.

\subsection{Quadratic least square regression}

Using the stepwise least square regression, the coefficients of eqn (6), are calculated using the three uniform designs U27(39), U36(39) and U51(39). The highest and the lowest residuals are observed with designs U27(39) and U51(39) respectively, as shown in Fig. 4. As shown in Fig. 5(a), the design U27(39) shows inverse linear proportionality of the energy pile thermal resistance with the five most significant factors. As shown in Fig. 5(a), the design $\mathrm{U}_{36}\left(3^{9}\right)$ shows inverse quadratic proportionality for the number of tubes " $n$ " and inverse linear proportionality for the other four significant factors. Both designs $U_{27}\left(3^{9}\right)$ and $U_{36}\left(3^{9}\right)$ did not detect any significance for the less significant factors; pile diameter " $d_{p}$ ", tube thickness " $t$ ", soil thermal conductivity " $K_{s}$ ", and the tube thermal conductivity " $K_{t}$ ". On the other hand, 
the comprehensive design $\mathrm{U}_{51}\left(3^{9}\right)$ has detected slight direct proportionality for the $R_{p}$ with the pile diameter " $d_{p}$ " and the tube thickness " $t$ ", as shown in Fig. 5(c).

\subsection{Model verification}

The coefficients of eqn (6), for using each design are shown in Table 4. The optimum conditions for minimum energy pile steady state thermal resistance are shown in Table 5. A test case with the optimum conditions is calculated using eqn (3) and using the quadratic models of eqn (6), using the coefficients listed in Table 4. The comparison of the results are shown in Table 5. The highest and the lowest errors are observed with designs $U_{27}\left(3^{9}\right)$ and $\mathrm{U}_{51}\left(3^{9}\right)$ respectively, as shown in Table 5. However, design $\mathrm{U}_{36}\left(3^{9}\right)$ shows appropriate error with simpler model and significantly low number of experiments.

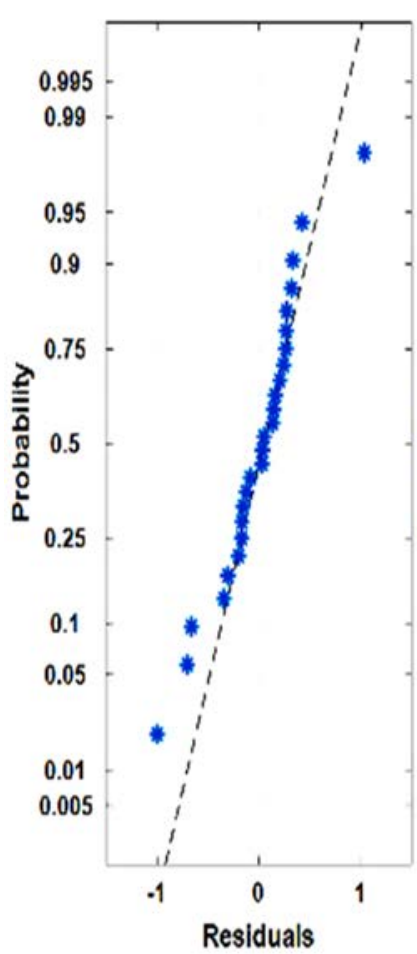

a) $\mathrm{U}_{27}\left(3^{9}\right)$

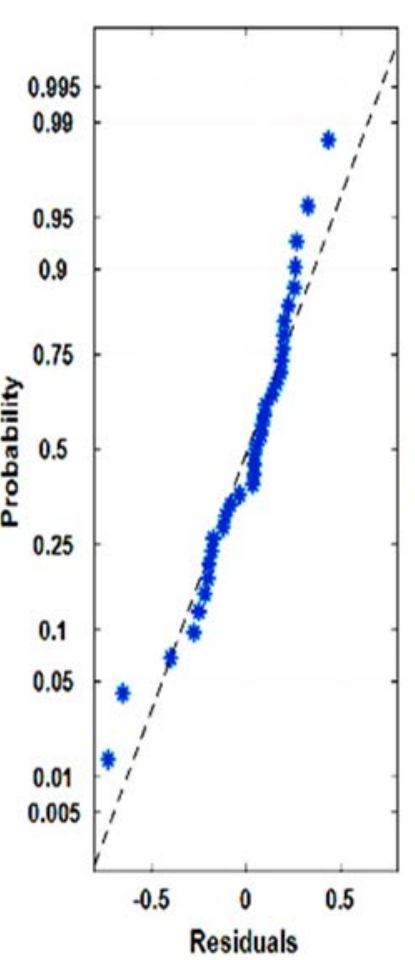

b) $U_{36}\left(3^{9}\right)$

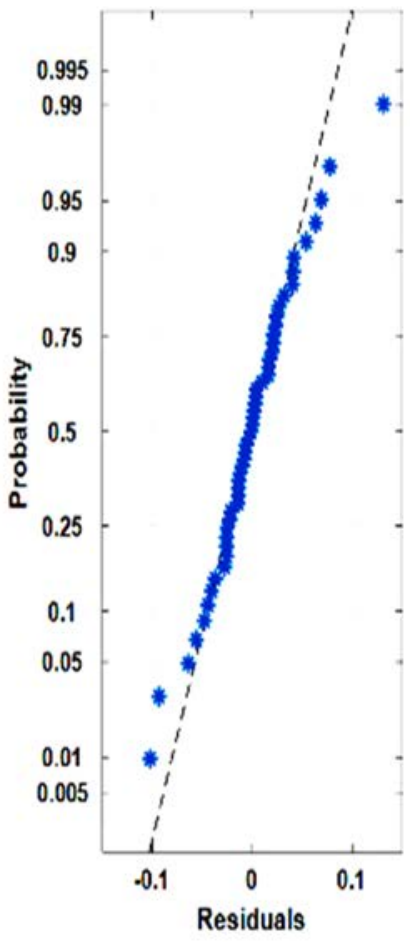

c) $\mathrm{U}_{51}\left(3^{9}\right)$

Figure 4: Residuals of the quadratic model predicted by the examined three designs. 


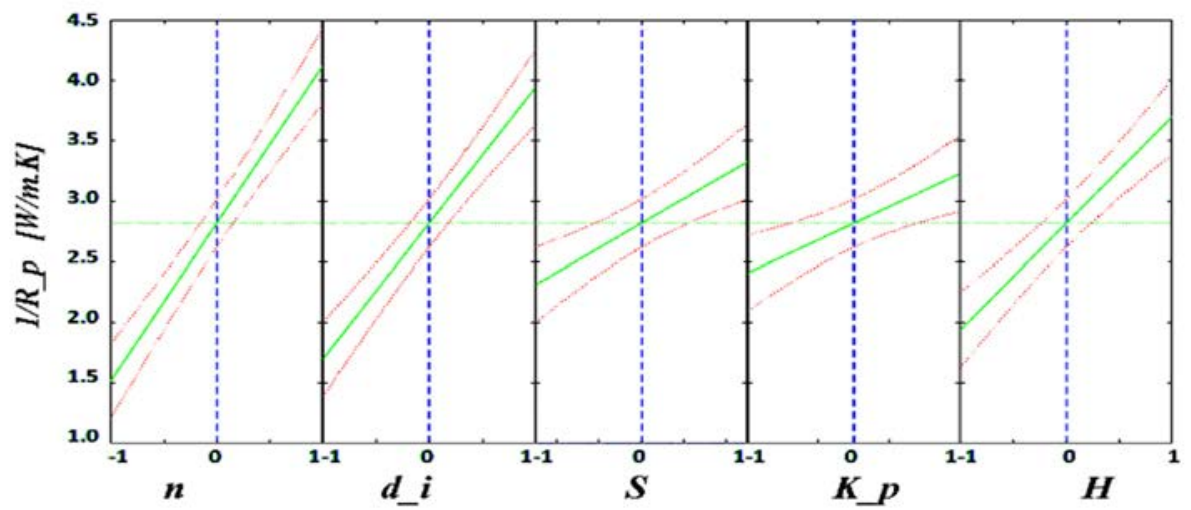

a) $\mathrm{U}_{27}\left(3^{9}\right)$

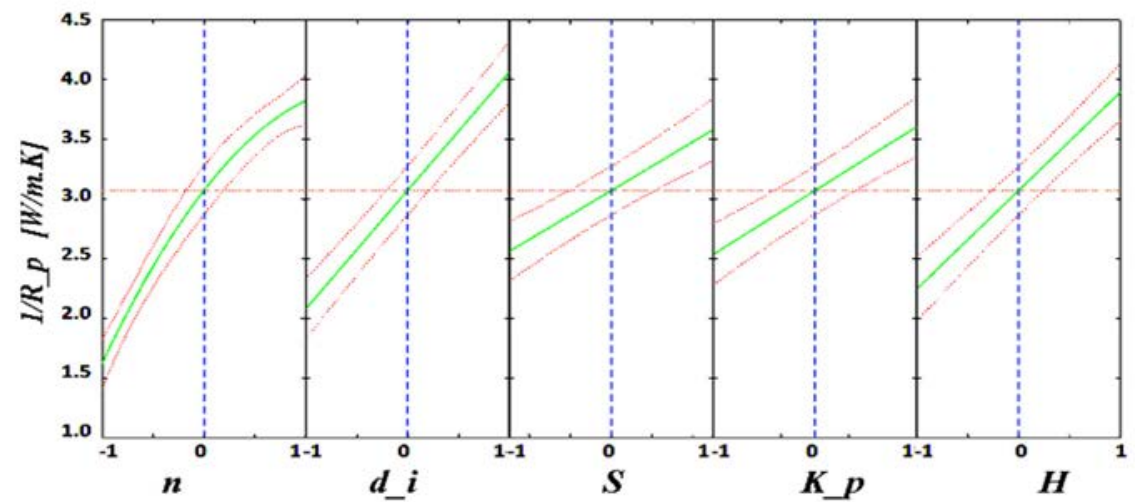

b) $\mathrm{U}_{39}\left(3^{9}\right)$

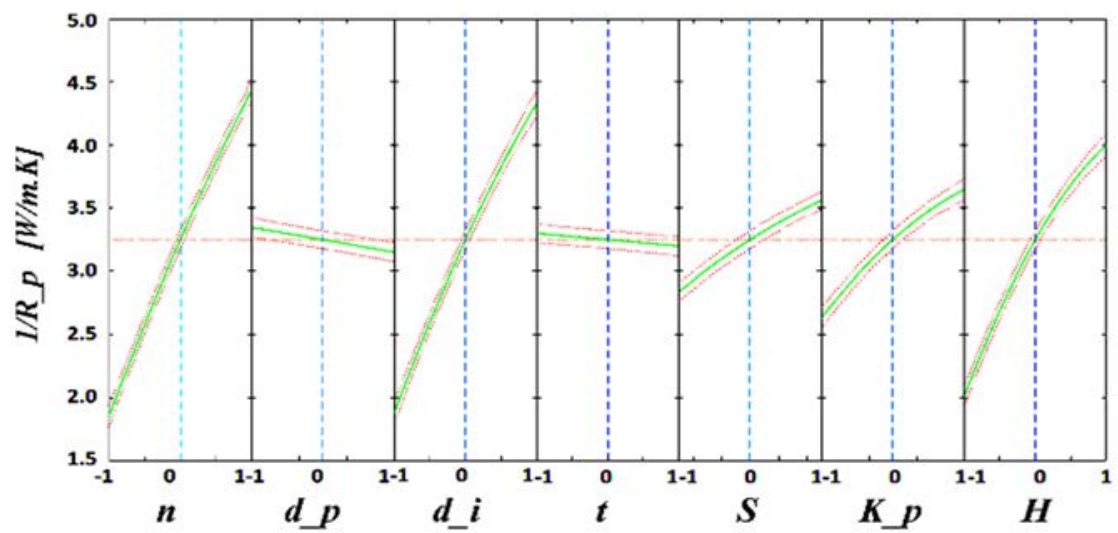

c) $\mathrm{U}_{51}\left(3^{9}\right)$

Figure 5: Effects of the most significant factors predicted by the examined three designs on the energy pile conductance. 
Table 4: The coefficients of the predicted quadratic regression model for the investigated three designs.

\begin{tabular}{|c|c|c|c|}
\hline $\begin{array}{l}\text { Regression } \\
\text { Coefficient }\end{array}$ & $U_{27}\left(3^{9}\right)$ & $U_{39}\left(3^{9}\right)$ & $U_{51}\left(3^{9}\right)$ \\
\hline Constant & -2.46951 & 4.105507 & 0.915396 \\
\hline$n$ & -0.17165 & -0.20913 & 0.601599 \\
\hline$d_{p}$ & 0 & 0 & -1.13405 \\
\hline$d_{i}$ & 23.53419 & -105.212 & -132.959 \\
\hline$t$ & 0 & 0 & -322.819 \\
\hline$S$ & -1.01491 & -2.27516 & 1.90682 \\
\hline$K_{p}$ & 0.546008 & -1.87604 & 1.372905 \\
\hline$H$ & 0.088139 & -0.14037 & -0.25675 \\
\hline$n^{2}$ & 0 & -0.08662 & -0.02662 \\
\hline$d_{i}^{2}$ & 0 & 0 & 4384.968 \\
\hline$S^{2}$ & 0 & 0 & -0.79398 \\
\hline$K_{p}^{2}$ & 0 & 0 & -0.19418 \\
\hline$H^{2}$ & 0 & 0 & 0.00638 \\
\hline$n * d_{i}$ & 22.10797 & 20.00451 & -17.1238 \\
\hline$n * S$ & 0.761437 & 0.697137 & -0.81543 \\
\hline$n * K_{p}$ & 0 & 0.2709 & -0.19484 \\
\hline$n * H$ & 0 & 0.011478 & 0.025657 \\
\hline$d_{p}{ }^{*} t$ & 0 & 0 & 389.0013 \\
\hline$d_{p} * K_{p}$ & 0 & 0 & -0.2044 \\
\hline$d_{i} * S$ & 0 & 0 & -97.9712 \\
\hline$d_{i}^{*} K_{p}$ & 0 & 33.48779 & 9.237119 \\
\hline$d_{i}^{*} H$ & 0 & 3.286897 & 15.42355 \\
\hline$S * H$ & 0 & 0.076152 & -0.00456 \\
\hline$K_{p} * H$ & 0 & 0.041763 & -0.02212 \\
\hline
\end{tabular}

Table 5: Optimum parameters and the calculated and predicted resistances using the three designs.

\begin{tabular}{|l|c|c|}
\hline$n:$ Number of U-tubes & +1 & 6 \\
\hline$d_{p}[\mathrm{~m}]:$ Pile diameter. & -1 & 0.4 \\
\hline$d_{i}[\mathrm{~m}]:$ Tube inner diameter & +1 & 0.03 \\
\hline$t[\mathrm{~m}]:$ Tube thickness & -1 & 0.02 \\
\hline$S[\mathrm{~m}]:$ Tubes spacing. & +1 & 0.3 \\
\hline$K_{p}[\mathrm{~W} / \mathrm{m} . \mathrm{K}]:$ Pile thermal conductivity. & +1 & 2.5 \\
\hline$K_{s}[\mathrm{~W} / \mathrm{m} . \mathrm{K}]:$ Soil thermal conductivity. & 0 & 1.0 \\
\hline
\end{tabular}

\begin{tabular}{|l|l|c|c|}
\hline \multicolumn{2}{|l|}{$K_{t}[\mathrm{~W} / \mathrm{m} . \mathrm{K}]:$ Tube thermal conductivity. } & 0 & 0.5 \\
\hline$H\left[\mathrm{~W} / \mathrm{m}^{2} . \mathrm{K}\right]:$ Heat transfer coefficient & +1 & 30 \\
\hline $1 / R_{p}:$ Energy pile Conductance $[\mathrm{W} / \mathrm{m} . \mathrm{K}]:$ & & 10.3 \\
\hline \multirow{3}{*}{$U D U_{n}\left(3^{9}\right)$ Prediction } & 27 Run $U_{27}\left(3^{9}\right)$ & $7.85($ Error $=23.8 \%)$ \\
\cline { 2 - 4 } & 36 Run $U_{39}\left(3^{9}\right)$ & $9.15($ Error $=11.3 \%)$ \\
\cline { 2 - 4 } & 51 Run $U_{51}\left(3^{9}\right)$ & $9.36($ Error $=9.5 \%)$ \\
\hline
\end{tabular}

\section{CONCLUSIONS}

Energy piles are crucial members of the GSHP system they reject or pump heat into the ground to reduce the consumption of fossil fuel and $\mathrm{CO}_{2}$ emission. The efficiency of the energy pile increases with the decrease of its steady state thermal resistance. The current work presents a statistical approach to define the optimum condition with the least number 
of experiments using uniform design. Three designs have been tested; $U_{27}\left(3^{9}\right), U_{36}\left(3^{9}\right)$, and $\mathrm{U}_{51}\left(3^{9}\right)$. The significance of each factor is measured by calculating the mean thermal resistance for each factor with all other factors. All three designs have shown consistent behaviour with the most significant factors. The most five significant factors with direct proportionality are the number of tubes " $n$ ", the tube inner diameter " $d_{i}$ ", the convection heat transfer coefficient " $H$ ", the pile thermal conductivity " $K_{p}$ ", and the distance between tubes " $S$ " respectively in significance order. The other four factors are either less significant or with inverse proportionality.

The calculated signal to noise ratios of these thermal resistances measured means of the energy pile at the different runs and using the different designs are analysed using smalleris-better Taguchi rule. The design $\mathrm{U}_{27}\left(3^{9}\right)$ shows high noise in all tested cases. The designs $\mathrm{U}_{36}\left(3^{9}\right)$ and $\mathrm{U}_{51}\left(3^{9}\right)$ have shown noises with the less significant factors.

Using the stepwise least square regression, the coefficients of the quadratic correlation are calculated using the three uniform designs $\mathrm{U}_{27}\left(3^{9}\right), \mathrm{U}_{36}\left(3^{9}\right)$ and $\mathrm{U}_{51}\left(3^{9}\right)$. The highest residuals are observed with design $\mathrm{U}_{27}\left(3^{9}\right)$ while the lowest residuals are observed with design $\mathrm{U}_{51}\left(3^{9}\right)$. Uniform design $\mathrm{U}_{36}\left(3^{9}\right)$ has shown acceptable levels of error with a significantly low number of experiments. The minimum energy pile steady state thermal resistance is achieved with the highest number of tubes, largest tube diameter, largest distance between tubes, highest pile thermal conductivity and highest heat transfer coefficient. Although, smaller pile diameter and smaller tube thickness slightly reduced the energy pile thermals resistance, the constructional limitation might stand against reducing these factors with a slight insignificant increase in the energy pile thermal resistance.

\section{ACKNOWLEDGEMENTS}

This publication was made possible by grant No. NPRP 7-725-2-270 from the Qatar National Research Fund (a member of Qatar Foundation). The statements made herein are solely the responsibility of the authors.

\section{REFERENCES}

[1] Kharseh, M., Al-Khawaja, M. \& Suleiman, M., Potential of ground source heat pump systems in cooling-dominated environments: residential buildings. Geothermic, 57, pp. 104-10, 2015.

[2] Brandl, H., Energy foundations and other thermo-active ground structures. Geotechnique, 56(2), pp. 81-122, 2006.

[3] Fadejev, J., Simson, R., Kurnitski, J. \& Haghighat, F., A review on energy piles design, sizing and modelling. Energy, 122, pp. 390-407, 2017.

[4] Haehnlein, S., Bayer, P. \& Blum, P., International legal status of the use of shallow geothermal energy. Renewable and Sustainable Energy Reviews, 14(9), pp. 2611-25, 2010.

[5] Hähnlein, S., Bayer, P., Ferguson, G. \& Blum, P., Sustainability and policy for the thermal use of shallow geothermal energy. Energy Policy. 59, pp. 914-25, 2013.

[6] Alcaraz, M., García-Gil, A., Vázquez-Suñé, E. \& Velasco, V., Use rights markets for shallow geothermal energy management. Applied Energy. 172, pp. 34-46, 2016.

[7] Karytsas, S.C. \& Chaldezos, I.P., Review of the Greek Legislative Framework for Ground Source Heat Pumps (GSHPs) and Suggestions for its Improvement. Procedia Environmental Sciences, 38, pp. 704-12, 2017.

[8] Cecinato, F. \& Loveridge, F., Influences on the thermal efficiency of energy piles. Energy, 82, pp. 1021-1033, 2015. 
[9] Hu, P., Zha, J., Lei, F., Zhu, N. \& Wu, T., A composite cylindrical model and its application in analysis of thermal response and performance for energy pile. Energy and Buildings, 84, pp. 324-332, 2014.

[10] Weissman, S.A. \& Anderson, N.G., Design of experiments (DoE) and process optimization. A review of recent publications. Organic Process Research \& Development. 19(11), pp. 1605-1633, 2014.

[11] Fang, K., Lin, D., Winker, P. \& Zhang, Y., Uniform design: theory and application. Technometrics, 42(3), pp. 237-248, 2000.

[12] Yang, J., Li, L., Yang, L. \& Li, J., Uniform design for the parameters optimization of pin-fins channel heat sink. Applied Thermal Engineering, 120, pp. 289-297, 2017.

[13] Fang, K. \& Wang, Y. (eds), Number-theoretic methods in statistics, CRC Press, 1993. 